\title{
Binding interaction between (-)-epigallocatechin gallate causes impaired spreading of cancer cells on fibrinogen
}

\author{
Yasuo Suzuki ${ }^{1}$ and Mamoru Isemura ${ }^{2}$ \\ ${ }^{1}$ Faculty of Human Life Sciences, Nagoya Keizai University, 61 Uchikubo, Inuyama Aichi 484-8504, Japan and ${ }^{2}$ Graduate School of \\ Nutritional and Environmental Sciences, University of Shizuoka, 52-1, Yada, Shizuoka 422-8526, Japan
}

(Received 7 October 2013; and accepted 17 October 2013)

\begin{abstract}
Green tea and tea catechins, especially (-)-epigallocatechin gallate (EGCG), have been shown to have various health benefits including anti-cancer, anti-metastasis, and anti-cardiovascular disease effects. Our previous studies demonstrated that three plasma proteins, fibronectin, histidine-rich glycoprotein, and fibrinogen were bound by EGCG, and that one specific domain in fibronectin was responsible for its binding interaction with EGCG. Fibrinogen consists of 6 chains linked by the disulfide bonds of two each of the $\alpha-, \beta$-, and $\gamma$-chains. The present study examined whether fibrinogen had a specific domain interacting with EGCG. The results of affinity chromatography under reducing conditions demonstrated that each of the $\alpha-, \beta$-, and $\gamma$-subunit chains of fibrinogen was bound by EGCG. We also demonstrated that several peptides generated by treatment with cyanogen bromide or thermolysin were bound by EGCG. The amino acid sequences analyzed revealed that these peptides included those derived from the $\alpha-, \beta$-, and $\gamma$-chains of fibrinogen. EGCG inhibited the spreading of mouse metastatic LL2-Lu3 lung cancer cells on the fibrinogen substratum, which suggested an impairment in the interaction between cancer cells and fibrinogen. Since the interaction between cancer cells and fibrinogen plays an important role in metastasis, the present results suggest, at least partially, that EGCG inhibited metastasis in the mouse models reported previously by inhibiting such an interaction.
\end{abstract}

Catechins are a group of polyphenolic compounds that occur naturally in certain species of plants and are found in green tea infusions. Our previous studies demonstrated that three plasma proteins, fibronectin, histidine-rich glycoprotein, and fibrinogen (18) were bound by (-)-epigallocatechin gallate (EGCG), and that one specific domain in fibronectin was responsible for its binding interaction with EGCG (17).

Fibrinogen is a high molecular weight glycoprotein found in plasma and consists of 6 chains linked

Address correspondence to: Dr. Mamoru Isemura Graduate School of Nutritional and Environmental Sciences, University of Shizuoka, 52-1, Yada, Shizuoka, 422-8526, Japan

Tel \& Fax: +81-54-264-5824

E-mail: isemura@u-shizuoka-ken.ac.jp by the disulfide bonds of two each of the $\alpha-, \beta-$, and $\gamma$-chains (15). It has been shown to have various biological roles including blood coagulation and metastasis $(4,14)$. In previous studies, peroral administration of an infusion of green tea and a catechin fraction mainly composed of EGCG was shown to prevent the metastasis of mouse Lewis lung carcinoma cells and melanoma B16F10 cells $(19,23)$. Therefore, the binding interaction of EGCG with fibrinogen may contribute to its inhibition of metastasis.

In the present study, we examined the interaction between EGCG and fibrinogen in more detail and also the effect of EGCG on the interaction between fibrinogen and tumor cells. 


\section{MATERIALS AND METHODS}

Chemicals. EGCG was obtained from Funakoshi Co. Ltd., Tokyo, Japan. EGCG was coupled to CNBractivated Sepharose 4B (Pharmacia Biotech, Tokyo, Japan) at a concentration of $5 \mathrm{mg} / \mathrm{mL}$ of wet gel as described previously (17). Thermolysin was obtained from Peptide Institute (Osaka, Japan), and was coupled to $\mathrm{CNBr}$-activated Sepharose $4 \mathrm{~B}$ at a concentration of $7 \mathrm{mg} / \mathrm{mL}$ of wet gel as described previously (17). Human fibrinogen and bovine fibrinogen were from Aldrich-Sigma. Alamar blue (a product of Alamar Biosciences, Sacramento, CA, USA) was from Asahi Techno Glass Corp., Tokyo, Japan. Serum-free cell culture medium Cosmedium 001 was purchased from Cosmo Bio Co. Ltd., Tokyo, Japan. Dithiothreitol (DTT) was from Nacalai Tesque, Kyoto, Japan. Highly metastatic mouse carcinoma LL2-Lu3 cells were obtained as described previously (16) and were cultured and maintained in a medium of $10 \%$ fetal bovine serum in Dulbecco's modified Eagle's medium (DMEM) with $50 \mathrm{U} / \mathrm{mL}$ penicillin, $50 \mu \mathrm{g} / \mathrm{mL}$ streptomycin, $2.5 \mu \mathrm{g} / \mathrm{mL}$ amphotericin $\mathrm{B}$, and $50 \mu \mathrm{g} / \mathrm{mL}$ gentamycin at $37^{\circ} \mathrm{C}$ under $5 \% \mathrm{CO}_{2}$ as described previously (19).

Interaction between fibrinogen subunits and EGCG. Human fibrinogen $(10 \mathrm{mg})$ was dissolved in $10 \mathrm{~mL}$ of Tris- $\mathrm{HCl}$ buffer ( $\mathrm{pH} 7.5$ ) and reduced with $10 \mathrm{mg}$ of DTT in the presence of $10 \mathrm{mM}$ EDTA at room temperature for $1 \mathrm{~h}$. The reduced fibrinogen was applied to a column of EGCG-agarose $(1.2 \times 2 \mathrm{~cm})$ equilibrated with Tris-HCl buffer containing $1 \mathrm{M}$ DTT. After washing with $50 \mathrm{mM}$ Tris-HCl buffer, the column was eluted with $4 \mathrm{M}$ urea/ $1 \mathrm{M} \mathrm{NaCl}$ in the same buffer and fractions were collected in each $1 \mathrm{~mL}$ portion using a fraction collector. The bound fractions thus obtained were examined by sodium dodecyl sulfate-polyacrylamide gel electrophoresis (SDS-PAGE) according to the method of Laemmli (7).

Interaction between $\mathrm{CNBr}$ fragments of fibrinogen and EGCG. Human fibrinogen $(100 \mathrm{mg})$ was dissolved in $1 \mathrm{~mL}$ of $70 \%$ formic acid and the fibrinogen solution was treated with $10 \mathrm{mg}$ of $\mathrm{CNBr}$ for $24 \mathrm{~h}$ at room temperature. After $20 \mathrm{~mL}$ of water was added to the mixture, the solution was freeze-dried. The materials obtained were dissolved in $0.15 \mathrm{M}$ ammonium bicarbonate containing $1 \mathrm{M}$ DTT and were centrifuged at $15,000 \mathrm{rpm}$ for $5 \mathrm{~min}$. The precipitates were discarded. The $\mathrm{CNBr}$ digest of fibrinogen thus obtained was loaded onto the EGCG-Sepharose column in $0.15 \mathrm{M}$ ammonium bicarbonate containing $1 \mathrm{M}$ DTT, and the bound fractions were eluted with $2 \mathrm{M}$ ammonium bicarbonate. The effluents were analyzed by SDS-PAGE.

Interaction between fibrinogen thermolytic peptides and EGCG. Bovine fibrinogen $(50 \mathrm{mg})$ was dissolved in $5 \mathrm{~mL}$ of $0.1 \mathrm{M}$ ammonium bicarbonate and digested with $1 \mathrm{~mL}$ of thermolysin immobilized on Sepharose $4 \mathrm{~B}$ at $37^{\circ} \mathrm{C}$ as described previously (17). The products generated by $1-\mathrm{h}$ and $24-\mathrm{h}$ digestions were examined by SDS-PAGE. The $1 \mathrm{~h}$-digestion products were incubated with $1 \mathrm{M}$ DTT in the presence of $10 \mathrm{mM}$ EDTA for $1 \mathrm{~h}$, and the mixture was loaded onto the EGCG-Sepharose column in a $50 \mathrm{mM}$ Tris-HCl buffer ( $\mathrm{pH} 7.5)$ containing $1 \mathrm{M}$ DTT and $1 \mathrm{mM}$ EDTA. After washing exhaustively with the buffer, the bound fractions were eluted with $2 \mathrm{M}$ ammonium carbonate and $2-\mathrm{mL}$ fractions were collected. The effluents were analyzed by SDSPAGE. When necessary, ammonium bicarbonate solutions were freeze-dried repeatedly to remove ammonium bicarbonate and then dissolved in the sample solution for SDS-PAGE under reducing conditions (17).

Determination of amino acid sequence. The partial amino acid sequences of fibrinogen fragments obtained by $\mathrm{CNBr}$ digestion or thermolysin digestion were determined after electroblotting on a polyvinylidene difluoride (PVDF) membrane (Boehringer Mannheim, Germany) using an Applied Biosystems model 470 sequencer as described previously (9).

Effect of EGCG on the interaction between carcinoma cells and fibrinogen. The effects of EGCG on cell adhesion to and the spreading of LL2-Lu3 cells on fibrinogen was examined as follows. Plastic 48well multidishes were coated with fibrinogen at $10 \mu \mathrm{g} / \mathrm{mL}$ in DMEM at $37^{\circ} \mathrm{C}$ for $30 \mathrm{~min}$. After being washed three times with $0.2 \mathrm{~mL}$ DMEM, fibrinogen-coated wells were blocked by incubation with $1 \%$ bovine serum albumin in DMEM at $37^{\circ} \mathrm{C}$ for $30 \mathrm{~min}$. After the wells were washed three times with DMEM, $0.1 \mathrm{~mL}$ of DMEM with or without EGCG at various concentrations was added and the wells were kept at $37^{\circ} \mathrm{C}$ for $30 \mathrm{~min}$. The wells were washed three times with serum-free cell culture medium Cosmedium 001, and freshly trypsinized LL2Lu3 cells $\left(1 \times 10^{4}\right.$ in $\left.0.1 \mathrm{~mL}\right)$ which had been washed three times with Cosmedium 001 were plated onto each well. The mixture was then incubated at $37^{\circ} \mathrm{C}$ in a humidified $\mathrm{CO}_{2}$ incubator. After $1 \mathrm{~h}$, the wells 
were washed three times with $0.5 \mathrm{~mL}$ of Cosmedium 001 and $0.1 \mathrm{~mL}$ of Cosmedium 001 was added. To examine cell adhesion, $10 \mu \mathrm{L}$ of Alamar blue solution was added to each well, and the mixture was incubated at $37^{\circ} \mathrm{C}$ in a $\mathrm{CO}_{2}$ incubator. After a 2-h incubation, fluorescence was measured with excitation at $560 \mathrm{~nm}$ and emission at $590 \mathrm{~nm}$ as described previously (20). Cells were photographed for the quantitative expression of cell spreading, and cells with a long spindle/short spindle ratio of 2 or more were counted as spread cells.

\section{RESULTS}

Human fibrinogen subunits bound by EGCG

We previously demonstrated that fibrinogen was bound by an EGCG column under non-reducing conditions. Since fibrinogen subunits are linked by disulfide bonds, whether each of the 3 subunits of fibrinogen had binding affinity for EGCG independently remained unknown. In the present study, we reduced human fibrinogen with DTT and examined the interaction of products with EGCG-agarose. Three protein bands of $54 \mathrm{kDa}(\gamma$-chain), $60 \mathrm{kDa}$ ( $\beta$-chain) and $68 \mathrm{kDa}(\alpha$-chain) were detected when the bound fractions were analyzed by SDS-PAGE (Fig. 1). These results indicated that each of the fibrinogen subunit chains ( $\alpha-, \beta$-, and $\gamma$-chains) was bound by EGCG independently.
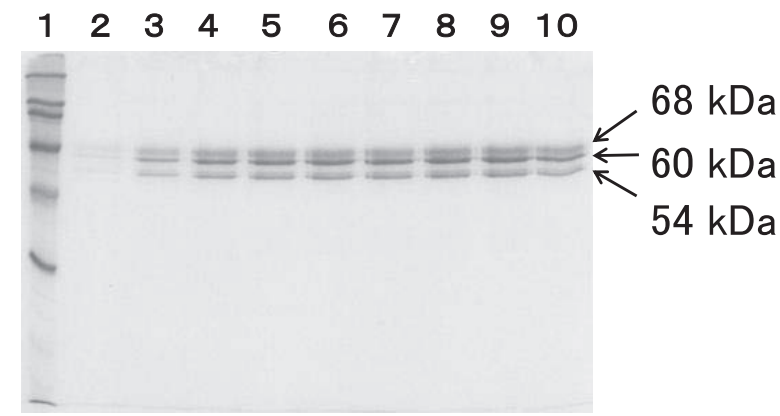

Fig. 1 SDS-PAGE of the EGCG-bound fraction of DTTtreated human fibrinogen subunits. Human fibrinogen reduced with DTT was applied to a column of EGCG-agarose. The bound fractions were eluted with Tris buffer containing $4 \mathrm{M}$ Urea /1 $\mathrm{M} \mathrm{NaCl}$ and subjected to SDS-PAGE. Molecular marker proteins (lane 1): rabbit muscle myosin $(220 \mathrm{kDa}), E$ coli $\beta$-galactosidase (116 kDa), rabbit muscle phosphorylase b $(97 \mathrm{kDa})$, bovine serum albumin $(66 \mathrm{kDa})$, chicken ovalbumin $(45 \mathrm{kDa})$, and bovine carbonic anhydrase $(29 \mathrm{kDa})$ from top to bottom. Lanes 2-10 represent fractions 1-9 eluted with $4 \mathrm{M}$ urea/ $1 \mathrm{M} \mathrm{NaCl}$, respectively. Proteins were stained with Coomassie brilliant blue R-250.
EGCG-bound fraction of human fibrinogen digested by $\mathrm{CNBr}$

Human fibrinogen was digested by $\mathrm{CNBr}$ and the digestion products were applied to an EGCG-agarose column. When the EGCG-bound fraction was analyzed by SDS-PAGE and electroblotting, the results indicated that $26 \mathrm{kDa}, 24 \mathrm{kDa}, 22 \mathrm{kDa}, 18 \mathrm{kDa}$, $15 \mathrm{kDa}$, and $12 \mathrm{kDa}$ fragments were bound by EGCG (Fig. 2). The $N$-terminal amino acid sequence of the $12 \mathrm{kDa}$ fragment was determined as FFSTYDRD(Table 1). This sequence was identical to that of the segment starting from $\mathrm{Phe}^{374}$ in the $\beta$ chain of fibrinogen. The sequence of the $22 \mathrm{kDa}$ fragment was determined as KYEASILTHDSSIRY-, which corresponded to the $N$-terminal sequence of the 15 residues in the segment starting from Lys ${ }^{95}$ in the $\gamma$ chain (Table 2). These peptides were generated by cleavage at the peptide bonds involving the carboxyl group of methionine, which was consistent with the specificity of the CNBr digestion (Tables 1 and 2).

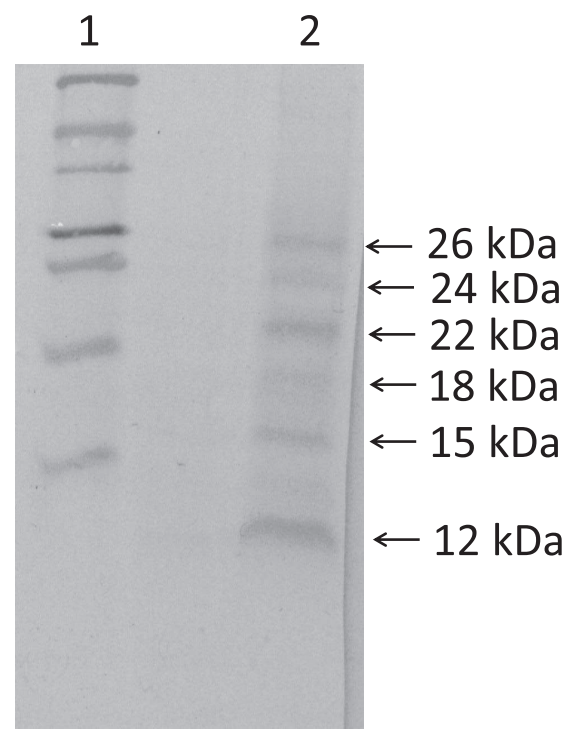

Fig. 2 Analysis of the EGCG-bound fragments derived from the $\mathrm{CNBr}$ digests of human fibrinogen. Human fibrinogen was digested with $\mathrm{CNBr}$ and the mixture was applied to an EGCG-agarose column. Electrically blotted proteins on a PVDF membrane were visualized by staining with Coomassie brilliant blue R-250. Lane 1, marker proteins; bovine serum albumin (66 kDa), egg albumin (45 kDa), glyceraldehyde-3-phosphate dehydrogenase $(36 \mathrm{kDa})$, bovine carbonic anhydrase (29 kDa), bovine pancreas trypsinogen (24 kDa), soybean trypsin inhibitor (20 kDa), and bovine milk $a$-lactoalbumin $(14.2 \mathrm{kDa})$ from top to bottom. Lane 2, the EGCGbound fraction of human fibrinogen digested by $\mathrm{CNBr}$. Proteins giving bands with molecular masses of $26 \mathrm{kDa}$, $24 \mathrm{kDa}, 22 \mathrm{kDa} 18 \mathrm{kDa}, 15 \mathrm{kDa}$, and $12 \mathrm{kDa}$ were subjected to amino acid sequence analysis. 
Table 1 Determined amino acid sequence of the $12 \mathrm{kDa}$ fragment derived from $\mathrm{CNBr}$ digestion products and the amino acid sequence of the human fibrinogen $\beta$-chain

\begin{tabular}{l}
\hline 12 kDa fragment FFSTYDRD- \\
\hline Human fibrinogen $\beta$-chain \\
1 QGVNDNEEGF FSARGHRPLD KKREEAPSLR PAPPPISGGG \\
41 YRARPAKAAA TQKKVERKAP DAGGCLHADP DLGVLCPTGC \\
81 QLQEALLQQE RPIRNSVDEL NNNVEAVSQT SSSSFQYMYL \\
121 LKDLWQKRQK QVKDNENVVN EYSSELEKHQ LYIDETVNSN \\
161 IPTNLRVLRS ILENLRSKIQ KLESDVSAQM EYCRTPCTVS \\
201 CNIPVVSGKE CEEIIRKGGE TSEMYLIQPD SSVKPYRVYC \\
241 DMNTENGGWT VIQNRQDGSV DFGRKWDPYK QGFGNVATNT \\
281 DGKNYCGLPG EYWLGNDKIS QLTRMGPTEL LIEMEDWKGD \\
321 KVKAHYGGFT VQNEANKYQI SVNKYRGTAG NALMDGASQL \\
361 MGENRTMTIH NGMFFSTYDR DNDGWLTSDP RKQCSKEDGG \\
401 GWWYNRCHAA NPNGRYYWGG QYTWDMAKHG TDDGVVWMNW \\
441 KGSWYSMRKM SMKIRPFFPQ Q \\
\hline
\end{tabular}

Table 2 Determined amino acid sequence of the $22 \mathrm{kDa}$ fragment and the complete amino acid sequence of the human fibrinogen $\gamma$-chain

\begin{tabular}{l}
\hline 22 kDa fragment KYEASILTHDSSIRY- \\
\hline Human fibrinogen $\gamma$-chain \\
1 YVATRDNCCI LDERFGSYCP TTCGIADFLS TYQTKVDKDL \\
41 QSLEDILHQV ENKTSEVKQL IKAIQLTYNP DESSKPNMID \\
81 AATLKSRIML EEIMKYEASI LTHDSSIRYL QEIYNSNNQK \\
121 IVNLKEKVAQ LEAQCQEPCK DTVQIHDITG KDCQDIANKG \\
161 AKQSGLYFIK PLKANQQFLV YCEIDGSGNG WTVFQKRLDG \\
201 SVDFKKNWIQ YKEGFGHLSP TGTTEFWLGN EKIHLISTQS \\
241 AIPYALRVEL EDWNGRTSTA DYAMFKVGPE ADKYRLTYAY \\
281 FAGGDAGDAF DGFDFGDDPS DKFFTSHNGM QFSTWDNDND \\
321 KFEGNCAEQD GSGWWMNKCH AGHLNGVYYQ GGTYSKASTP \\
361 NGYDNGIIWA TWKTRWYSMK KTTMKIIPFN RLTIGEGQQH \\
401 HLGGAKQAGD V
\end{tabular}

Thermolysin peptides from bovine fibrinogen bound by $E G C G$

When bovine fibrinogen was digested with thermolysin, digestion for $1 \mathrm{~h}$ gave several bands on SDSPAGE (Fig. 3). These fragments were also detected in the 24-h digestion products, which suggested that these thermolysin peptides were strongly resistant to further digestion, presumably representing the domain structures in fibrinogen. When the 1-h digestion products were examined for the binding interaction with EGCG, the results of SDS-PAGE indicated that $51 \mathrm{kDa}, 46 \mathrm{kDa}, 36 \mathrm{kDa}$, and $28 \mathrm{kDa}$ fragments were bound by EGCG (Fig. 4). After blotting onto a
PVDF membrane, these peptides were subjected to amino acid sequence analysis. The results indicated that the $28 \mathrm{kDa}$ fragment was derived from the segment starting from $\mathrm{Leu}^{23}$ in the $\alpha$-chain (Table 3). Similarly, the $36 \mathrm{kDa}$ fragment was considered to have been derived from the segment starting from $\mathrm{Tyr}^{1}$ in the $\gamma$-chain (Table 4). These results indicated that the $\alpha$ - and $\gamma$-chains of bovine fibrinogen possess respective binding sites for EGCG.

Cell adhesion to and cell spreading on EGCG-treated fibrinogen

To examine whether the binding association of 


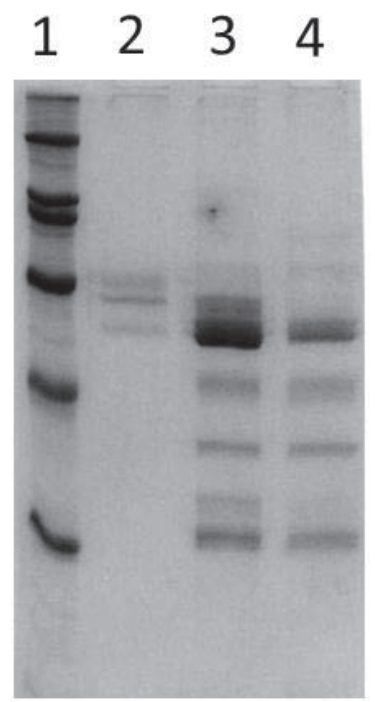

Fig. 3 SDS-PAGE of the thermolytic peptides derived from bovine fibrinogen. Bovine fibrinogen was digested with thermolysin for different periods of time. The products were analyzed by SDS-PAGE. Lane 1, marker proteins as used in Fig. 1; lane 2, bovine fibrinogen; lane 3, 1-h digestion products; lane 4, 24-h digestion products.

EGCG with fibrinogen affected the interaction between fibrinogen and tumor cells, we investigated the effects of EGCG on cell adhesion and spreading of LL2-Lu3 cells on the fibrinogen substratum. These cells attached to and spread on plastic dishes coated with fibrinogen. Although EGCG did not interfered with cell attachment to the fibrinogencoated dishes, the spreading of these cells on fibrinogen-treated dishes was inhibited by prior treatment with EGCG (Fig. 5).

\section{DISCUSSION}

Fibrinogen is a major plasma protein of $350 \mathrm{kDa}$ and consists of $6 \mathrm{~S}$-S-linked subunit chains of 2 $\alpha$-chains, $2 \beta$-chains, and $2 \gamma$-chains (15). It has been shown to play an important role in blood clotting, cellular and matrix interactions, inflammation, wound healing, and neoplasia $(4,14)$. Fibrinogen was also shown to induce proliferative signals by serving as a scaffold to support the binding of growth factor and promote the cellular responses of adhesion, proliferation, and migration during wound healing, angiogenesis, and tumor growth $(1,2,4$, $22)$. We previously reported that three plasma proteins including fibrinogen were bound by EGCG (18). Hung et al. also demonstrated the binding interaction of EGCG with fibrinogen, which inhibited the adhesion of human foreskin fibroblasts to the

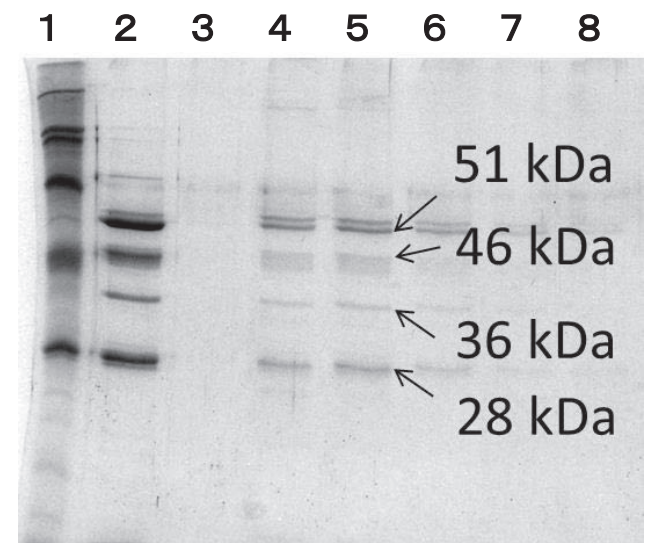

Fig. 4 SDS-PAGE of EGCG-unbound and EGCG-bound peptides in the thermolysin digestion products of bovine fibrinogen. Products obtained by the $1-\mathrm{h}$ digestion were applied to the EGCG-agarose column. Proteins were visualized by staining with Coomassie brilliant blue R-250. Lane 1, marker proteins as used in Fig. 1. Lane 2, EGCG-unbound fraction. Lanes 3-8, EGCG-bound fractions 1-6, respectively.

substratum (5). However, it remains unclear whether the binding of EGCG to fibrinogen causes an impairment in tumor cell adhesion and/or spreading, which are important for tumor cell invasion and metastasis. In the present study, we examined whether EGCG caused any impairment in the interaction between tumor cells and fibrinogen.

To obtain further evidence to indicate the interaction between fibrinogen and EGCG, we examined whether each of the 3 subunit chains $(\alpha-, \beta$-, and $\gamma$-chains) of fibrinogen had an EGCG-binding site. The results of affinity chromatography under reducing conditions suggested that each of the subunit chains possessed at least one specific site bound by EGCG. Consistent with this finding, it was further demonstrated that the $\mathrm{CNBr}$ fragments derived from the $\beta$ - and $\gamma$-chains of human fibrinogen and those derived from the $\alpha$ - and $\gamma$-chains of bovine fibrinogen generated by thermolysin digestion were bound by EGCG as discussed below.

The $12 \mathrm{kDa}$ human fibrinogen fragment derived from $\mathrm{CNBr}$-digestion products was found to be bound by the EGCG column. Its $N$-terminal 8 amino acid sequence corresponded to that of the segment starting from $\mathrm{Phe}^{374}$ in the $\beta$-chain. The $22 \mathrm{kDa}$ human fibrinogen fragment derived from the $\gamma$-chain was also shown to be bound by EGCG. The amino acid sequences of other fragments could not be determined. Although the reason for this remains unclear, one possible explanation may be the blocking of their $\mathrm{N}$-terminals by the formation of a pyroglutamyl residue after the non-specific cleavage of pep- 
Table 3 The amino acid sequence of the $28 \mathrm{kDa}$ fragment and the complete amino acid sequence of the bovine fibrinogen a-chain

\begin{tabular}{l}
\hline 28 kDa fragment LVERQQSACKETGWPF- \\
\hline Bovine fibrinogen $\alpha$-chain \\
1 SDPPSGDFLT EGGGVRGPRL VERQQSACKE TGWPFCSDED \\
41 WNTKCPSGCR MKGLIDEVDQ DFTSRINKLR DSLFNYQKNS \\
81 KDSNTLTKNI VELMRGDFAK ANNNDNTFKQ ISEDLRSRIE \\
121 ILRRKVIEQV QRIKVLQKNV RDQLVDMKRL EVDIDIKIRS \\
161 CKGSCSRALE HKVDLEDYKN QQKQLEQVIA INLLPSRDIQ \\
201 YLPLIKMSTI TGPVPREFKS QLQEAPLEWK ALLEMQQTKM \\
241 VLETFGGDGH ARGDSVSQGT GLAPGSPRKP GTSSIGNVNP \\
281 GSYGPGSSGT WNPGRPEPGS AGTWNPGRPE PGSAGTWNPG \\
321 RPEPGSAGTW NPGRPEPGSA GTWNPGRPEP GSAGTWNTGS \\
361 SGSSSFRPDS SGHGNIRPSS PDWGTFREEG SVSSGTKQEF \\
401 HTGKLVTTKG DKELLIDNEK VTSGHTTTR RSCSKVITKT \\
441 VTNADGRTET TKEVVKSEDG SDCGDADFDW HHTFPSRGNL \\
481 DDFFHRDKDD FFTRSSHEFD GRTGLAPEFA ALGESGSSSS \\
521 KTSTHSKQFV SSSTTVNRGG SAIESKHFKM EDEAESLEDL \\
561 GFKGAHGTQK GHTKARPARG IHTSPLGEPS LTP
\end{tabular}

Table 4 The amino acid sequence of the $36 \mathrm{kDa}$ fragment and the complete amino acid sequence of the bovine fibrinogen $\gamma$-chain

\begin{tabular}{l}
\hline 36 kDa fragment YVATRDNCCILDERFG- \\
\hline Bovine fibrinogen $\gamma$-chain \\
1 YVATRDNCCI LDERFGSYCP TTCGIADFLN NYQTSVDKDL \\
41 RTLEGILYQV ENKTSEAREL VKAIQISYNP DQPSKPNNIE \\
81 SATKNSKSMM EEIMKYETLI STHESTIRFL QEVYNSNSQK \\
121 IVNLRDKVVQ LEANCQEPCQ DTVKIHDVTG RDCQDVANKG \\
161 AKESGLYFIR PLKAKQFLVY CEIDGSGNGW TVFQKRLDGS \\
201 LDFKKNWIQY KEGFGHLSPT GTGNTEFWLG NEKIHLISTQ \\
241 SSIPYVLRIQ LEDWNGRTST ADYASFKVTG ENDKYRLTYA \\
281 YFIGGDAGDA FDGYDFGDDS SDKFFTSHNG MQFSTWDSDN \\
321 DKYDGNCAEQ VGIGWWMNKC HAGHLNGVYY QGGTYSKTST \\
361 PNGYDNGIIW ATWKSRWYSM KKTTMKIIPL NRLAIGEGQQ \\
401 HQLGGAKQVG VEHHVEIEYD
\end{tabular}

tide bonds in which the amino group of the glutamic acid residue was involved. Since evidence for the binding interaction of a fragment derived from the $\alpha$-chain was not obtained by the experiment using $\mathrm{CNBr}$-peptides derived from human fibrinogen, we next examined the fragments obtained by the thermolysin digestion of bovine fibrinogen.

Among the thermolytic fragments obtained, the $28 \mathrm{kDa}$ and $36 \mathrm{kDa}$ fragments were bound by EGCG. The determined amino acid sequence indicated that the $28 \mathrm{kDa}$ fragment was derived from the $\alpha$-chain, and the $36 \mathrm{kDa}$ fragment was considered to be derived from the $\gamma$-chain. These results indicated that each of three fibrinogen subunits had at least one EGCG-binding site independent of the other subunits.

EGCG has been shown to interact with several proteins at specific molecular sites. For example, EGCG was proposed to inhibit urokinase by fitting into the catalytic cavity formed with $\mathrm{His}^{57}, \mathrm{Asp}^{102}$, 


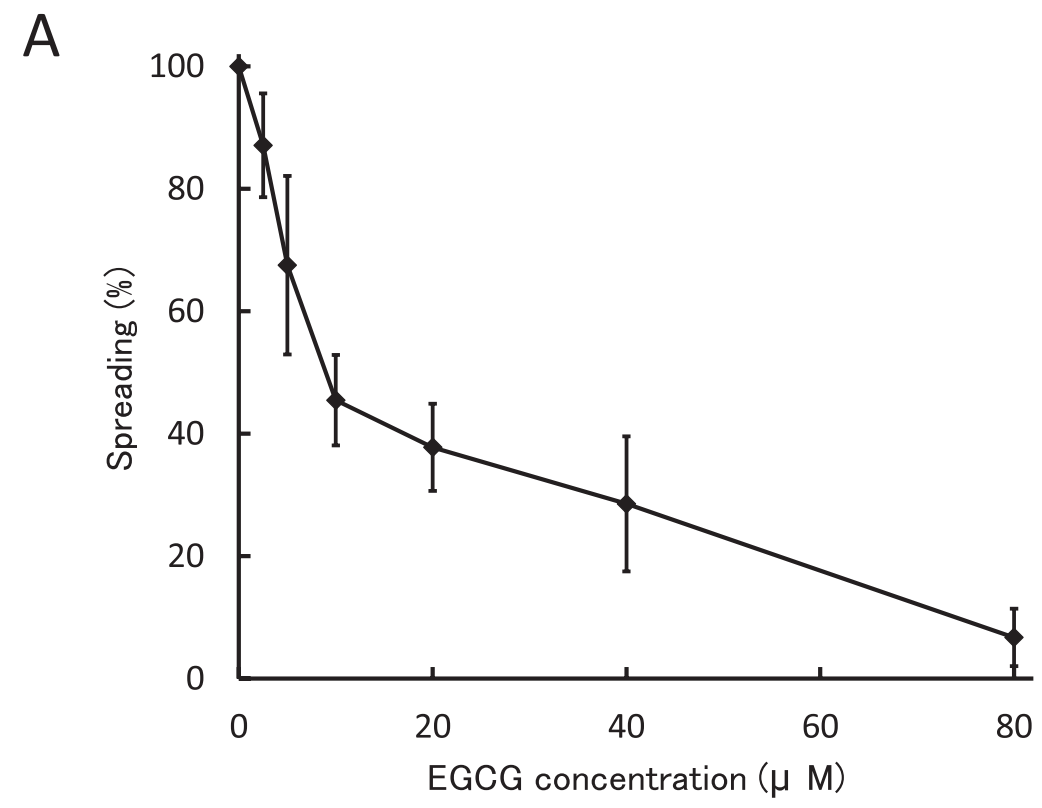

B
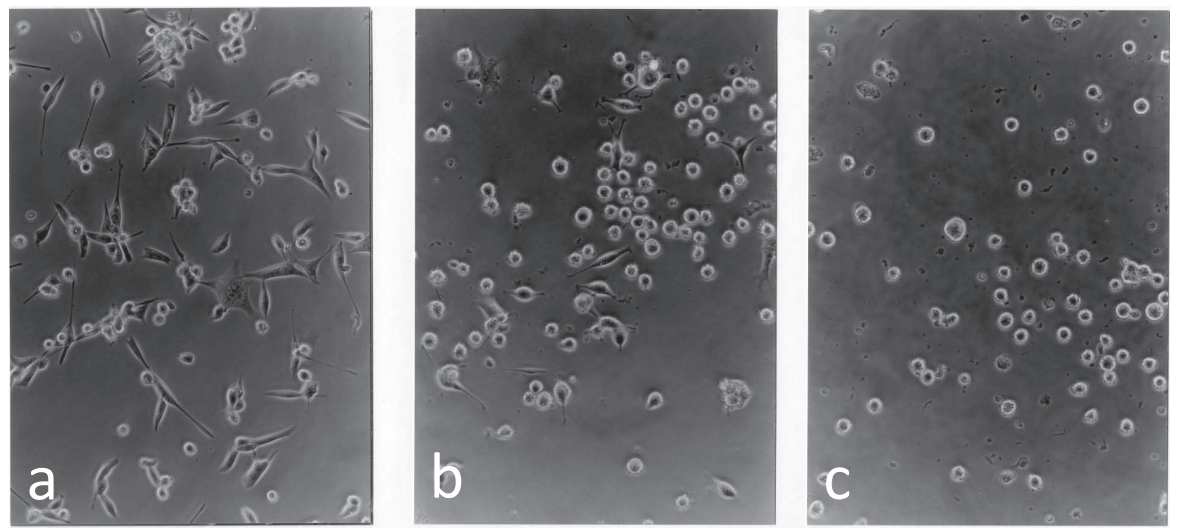

Fig. 5 Effects of EGCG on spreading of LL2-Lu3 cells on fibrinogen. A, plastic multidishes with 48 wells coated with fibrinogen were treated with EGCG at various concentrations. The wells were washed to remove unbound EGCG and freshly trypsinized LL2-Lu3 cells were plated to an each well. After a 60-min incubation, cells were photographed and spreading cells with a long spindle/short spindle ratio of 2 or more were counted. Data presented are averages \pm S.D. from triplicate cultures. B, a representative photograph taken after the 60-min incubation showing cell spreading on fibrinogen pre-treated with EGCG at $20 \mu \mathrm{M}$ (b) and $80 \mu \mathrm{M}$ (c) was less than that on the fibrinogen substratum without the EGCG treatment (a).

$\mathrm{Ser}^{195}$, and $\mathrm{Arg}^{35}$ (6) and DNA methyltransferase by formation of hydrogen bonds with the residues $\mathrm{Pro}^{1223}$, Glu ${ }^{1265}, \mathrm{Cys}^{1225}, \mathrm{Ser}^{1229}$, and $\operatorname{Arg}^{1309}$ (3). Fibrinogen appears to have at least one such binding pocket in each of the three subunit chains, although it is not known what amino acid residues of fibrinogen subunits are involved in the interaction with EGCG. Future studies are needed to reveal the nature of their binding affinity.

In experiments to examine whether EGCG affected the cellular activity such as cell adhesion and spreading on fibrinogen substrata, EGCG was ob- served to inhibit the spreading of mouse lung carcinoma LL2-Lu2 cells, but not cell adhesion. The various roles of fibrinogen or fibrin on tumor progression and metastasis have been demonstrated previously. Palumbo et al. reported that a genetic fibrinogen deficiency strongly diminished the development of lung metastasis in both Lewis lung carcinoma and B16-BL6 melanoma lung metastatic models (14). Ma et al. demonstrated that plasma fibrinogen levels were associated with peritoneal carcinomatosis of ovarian carcinoma (10). Takeuchi et al. also revealed that higher levels of fibrinogen in 
the plasma correlated with tumor progression and metastasis in patients with esophageal squamous cell carcinoma (22). More recently, Lee et al. reported an association between pre-operative plasma fibrinogen levels and adjacent organ involvement in advanced gastric cancer (8). These findings suggest that therapeutic strategies directed at fibrinogen may be useful for suppressing metastatic disease (13) and that EGCG, which causes an impairment in fibrinogen activity leading to the inhibition of cancer cell spreading on it, may be a candidate for an inhibitor of tumor cell metastasis, as has been reported in the previous studies $(19,23)$.

The concentration of EGCG in human plasma was estimated to be $2-4 \mu \mathrm{M}$ after its oral administration $(11,24)$. The required concentration for EGCG to inhibit cell spreading on fibrinogen was at least one order higher than this level. Our previous studies showed that EGCG inhibited cell adhesion and spreading on fibronectin and laminin at higher doses than that of the physiologically available dose (12, 21). Thus, these and the present findings suggest that previously observed in vivo inhibition of metastasis elicited by EGCG (23) and the green tea infusion (19) may have resulted from a combination of the effects of EGCG caused by its binding interaction with fibronectin, laminin, and fibrinogen.

\section{REFERENCES}

1. Akakura N, Hoogland C, Takada YK, Saegusa J, Ye X, Liu FT, Cheung AT and Takada Y (2006) The COOH-terminal globular domain of fibrinogen $\gamma$ chain suppresses angiogenesis and tumor growth. Cancer Res 66, 9691-9697.

2. Cheresh DA, Berliner SA, Vicente V and Ruggeri ZM (1989) Recognition of distinct adhesive sites on fibrinogen by related integrins on platelets and endothelial cells. Cell 58, 945953.

3. Fang MZ, Wang Y, Ai N, Hou Z, Sun Y, Lu H, Welsh W and Yang CS (2003) Tea polyphenol (-)-epigallocatechin-3-gallate inhibits DNA methyltransferase and reactivates methylationsilenced genes in cancer cell lines. Cancer Res 15, 75637570 .

4. Fitzgerald DJ (1999) Fibrinogen receptor and platelet signalling. Blood Coagul Fibrinolysis 10, Suppl. 1: S77-S79.

5. Hung CF, Huang TF, Chiang HS and Wu WB (2005) (-)-Epigallocatechin-3-gallate, a polyphenolic compound from green tea, inhibits fibroblast adhesion and migration through multiple mechanisms. J Cell Biochem 96, 183-197.

6. Jankun J, Selman SH, Swiercz R and Skrzypczak-Jankun E (1997) Why drinking green tea could prevent cancer. Nature 387, 561 .

7. Laemmli UK (1970) Cleavage of structural proteins during the assembly of the head of bacteriophage T4. Nature 227, 680-685.

8. Lee SE, Lee JH, Ryu KW, Nam BH, Cho SJ, Lee JY, Kim CG, Choi IJ, Kook MC, Park SR and Kim YW (2012) Preoperative plasma fibrinogen level is a useful predictor of ad- jacent organ involvement in patients with advanced gastric cancer. J Gastric Cancer 12, 81-87.

9. Matsudaira P (1987) Sequence from picomole quantities of proteins electroblotted onto polyvinylidene difluoride membranes. J Biol Chem 262, 10035-10038.

10. Ma Y, Qian Y and Lv W (2007) The correlation between plasma fibrinogen levels and the clinical features of patients with ovarian carcinoma. J Int Med Res 35, 678-684.

11. Nakagawa K, Okuda S and Miyazawa T (1997) Dose-dependent incorporation of tea catechins, (-)-epigallocatechin-3gallate and (-)-epigallocatechin, into human plasma. Biosci Biotechnol Biochem 61, 1981-1985.

12. Ogata K, Mukae N, Suzuki Y, Satoh K, Narumi K, Nukiwa $\mathrm{T}$ and Isemura M (1995) Effects of catechins on the mouse tumor cell adhesion to fibronectin. Planta Med 61, 472-474.

13. Palumbo JS and Degen JL (2001) Fibrinogen and tumor cell metastasis. Haemostasis 31, Suppl 1:11-15.

14. Palumbo JS, Kombrinck KW, Drew AF, Grimes TS, Kiser JH, Degen JL and Bugge TH (2000) Fibrinogen is an important determinant of the metastatic potential of circulating tumor cells. Blood 96, 3302-3309.

15. Park SJ and Khang D (2012) Conformational changes of fibrinogen in dispersed carbon nanotubes. Int J Nanomedicine, 7, 4325-4333.

16. Sazuka M, Imazawa H, Shoji Y, Mita T, Hara Y and Isemura M (1997) Inhibition of collagenases from mouse lung carcinoma cells by green tea catechins and black tea theaflavins. Biosci Biotechnol Biochem 61, 1504-1506.

17. Sazuka M, Isemura M and Isemura S (1998) Interaction between the carboxyl-terminal heparin-binding domain of fibronectin and (-)-epigallocatechin gallate. Biosci Biotechnol Biochem 62, 1031-1032.

18. Sazuka M, Itoi T, Suzuki Y, Odani S, Koide T and Isemura M (1996) Evidence for the interaction between (-)-epigallocatechin gallate and human plasma proteins fibronectin, fibrinogen, and histidine-rich glycoprotein. Biosci Biotechnol Biochem 60, 1317-1319.

19. Sazuka M, Murakami S, Isemura M, Satoh K and Nukiwa T (1995) Inhibitory effects of green tea infusion on in vitro invasion and in vivo metastasis of mouse lung carcinoma cells. Cancer Lett 98, 27-31.

20. Shoji Y, Aoyagi Y, Kawakami T, Isemura S and Isemura M (1999) Cell adhesion activity for murine carcinoma cells of a wheat germ $55-\mathrm{kDa}$ protein with binding affinity for animal extracellular matrix proteins. Biochim Biophys Acta 1426, 498-504.

21. Suzuki Y and Isemura M (2001) Inhibitory effect of epigallocatechin gallate on adhesion of murine melanoma cells to laminin. Cancer Lett 173, 15-20.

22. Takeuchi H, Ikeuchi S, Kitagawa Y, Shimada A, Oishi T, Isobe Y, Kubochi K, Kitajima M and Matsumoto S (2007) Pretreatment plasma fibrinogen level correlates with tumor progression and metastasis in patients with squamous cell carcinoma of the esophagus. $J$ Gastroenterol Hepatol 22, 2222-2227.

23. Taniguchi S, Fujiki H, Kobayashi H, Go K, Miyado H, Sadano H and Shimokawa R (1992) Effect of (-)-epigallocatechin gallate, the main constituent of green tea, on lung metastasis with mouse B16 melanoma cell lines. Cancer Lett 65, 51-54.

24. Yang CS, Chen L, Lee MJ, Balentine D, Kuo MC and Schantz SP (1998) Blood and urine levels of tea catechins after ingestion of different amounts of green tea by human volunteers. Cancer Epidemiol Biomarkers Prev 7, 351-354. 